\title{
Green Affordable Social Housing: A Survey-Based Passive Cooling Design, with Focus on Jakande Housing Estate in Lagos, Nigeria
}

\author{
Justus Anih Nzube, Aimin Lyu \\ School of Design, Shanghai Jiao Tong University, Shanghai, China \\ Email: anihnzubej@sjtu.edu.cn, aiminlv@sjtu.edu.cn
}

How to cite this paper: Nzube, J.A. and Lyu, A. (2021) Green Affordable Social Housing: A Survey-Based Passive Cooling Design, with Focus on Jakande Housing Estate in Lagos, Nigeria. World Journal of Engineering and Technology, 9, 848-860. https://doi.org/10.4236/wjet.2021.94058

Received: October 13, 2021

Accepted: November 8, 2021

Published: November 11, 2021

\begin{abstract}
With rising health risks escalating from temperatures in the Global South, the shortage of essential indoor cooling is frequently seen as a dimension of energy poverty and human wellbeing. As a result, this study assessed ventilation and passive cooling in Jakande, Lagos Housing estate to design social housing that integrates proper cross ventilation and cooling. A total of 1215 housing units in the estate were used for the sampling frame. Based on the survey, the authors proposed an analytical housing design equipped with urban greenery that allows for free air movement with minimal thermal discomfort. The design methodology aids continuous cooling within the housing envelope and also improves aesthetics and landscaping within the environment.
\end{abstract}

\section{Keywords}

Affordable Housing, Climate Change, Green Building, Landscaping, Passive Cooling, Social Housing, Sustainable Energy

\section{Introduction}

In several areas of the world, human exposure to extreme heat is at unprecedented levels and is expected to rise with increasing global temperatures. A 2017 study predicts that if carbon emissions continue on their current trajectory, three-quarters of humanity will face deadly heat by the end of the century [1]. Moreover, urban dwellers, including high, middle, and low-income earners, desire to live in a suitable, convenient, and well-ventilated environment. However, with the increase in heat waves resulting from a change in climate, urban dwellers have switched over to mechanical cooling systems such as air conditioners, 
cooling fans, etc. Obviously, these mechanical cooling systems are unsustainable, and most importantly, environmentally unfriendly.

Owing to the above-cited issues, green building has gradually been publicized and implemented in numerous countries, and has become the main focus of development in the building industry [2] [3]. Over the last decade, scholars have progressively researched on the design of green building [4], with focus on the transformation of traditional buildings into green buildings. However, in most developing countries with the most extensive and fastest-growing building markets coupled with economic crisis, transformational objectives of traditional buildings into affordable green buildings, are primarily neglected [5]. A perfect example is the current state of the unaffordable estate housing sector of Lagos, Nigeria [6] [7]. At present, the Lagos housing deficit is estimated at 5 million homes, representing $31 \%$ of the estimated national housing deficit of 18 million [8] [9]. As a result, the few housing available is costly and expensive, and this has led poor residents to revert to informal procurement procedures for accommodation. Beside the dwelling conditions of income earners in Lagos, residents are also confronted with energy crisis. According to the Nigerian Electricity Regulatory Commission, only $45 \%$ of electricity customers have meters [10]. The absence of meters and inaccurate utility bills for consumers has often resulted in over-billing for electricity used, resulting in consumers' refusal to honor the bills. Ultimately, utility providers incur large outstanding bills and debts which constrain their future ability to supply electricity [11]. Due to the epileptic supply of electricity, a vast majority of households in Nigeria, have resulted into bio-fuels for cooling buildings not undermining the exuberant cost of fueling gasoline generators. Thus, low income earners in Lagos, actually find house cooling a difficult and challenging task. It is therefore eminent and needful to provide affordable green social housing facilities for the low-income earners of Lagos.

As pointed out in [12], a crucial condition for the construction of green buildings is the integration and innovation of passive cooling systems. Passive cooling refers to any technology or design features adopted to reduce buildings' temperature without the need for power consumption [13]. The passive architecture responds to the local environment and site conditions to optimize the comfort and health of building users while minimizing the use of energy. The basics to designing a passive building are to take the local climate's best advantage. An effective passive cooling system uses free sources of renewable energy, such as the sun, wind, and natural vegetation to provide ventilation, and lighting needs for a home. This further reduces the need for mechanical cooling such as air conditioning systems. Applying passive cooling means reducing differences between outdoor and indoor temperatures, improving indoor air quality, and building a better and more comfortable environment to live or work in. As stated in [14], buildings account for about $70 \%$ of the electricity load, $40 \%$ of all energy consumption, and $40 \%$ of $\mathrm{CO}_{2}$ emissions. Hence, making buildings more energy-efficient can be one of the fastest and the most cost-effective method of lowering emissions of greenhouse gases. 
Motivated by the above discussion, this study is centered on applying the concept of green building for social housing design to improve artificial passive cooling that is cheap and affordable for the study area (Jakande Estates). The objectives are to: 1) Assess the socio-economic characteristics of residents, and examine the state of ventilation and type of ventilation systems in the Jakande housing estate. 2) Examine the level of indoor comfort derived from existing ventilation available, and investigate the impact of existing ventilation systems on residents. 3) Survey the social challenges to natural ventilation and passive cooling in the housing estate, and out of the survey results, design an affordable green passive cooling social housing for the study area.

The rest of the paper is organized as follows. The research design is presented in Section 2. This section describes the methodological framework used in attaining the stated aims and objectives of the research, and analyse the data obtained from the field. Section 3 presents the design and simulation results of the proposed green passive cooling social housing for the study area. In Section 4, the discussions of the survey data and recommendations are presented. Finally, Section 5 presents the concluding remarks.

\section{Research Design}

\subsection{Source of Data}

The two types of data collected for this study include; primary and secondary data. The primary data is obtained from residents living in Abesan Jakande Estate. The full survey obtains data on the socio-economic characteristics of residents in the study area, state of ventilation and type of ventilation systems, the level of indoor comfort derived from existing ventilation available and the system, the impact of existing ventilation systems on residents, and the design, social challenges, and the expectations for natural ventilation and passive cooling in the study area. The primary data types are captured in Table 1.

Secondary source of data to be obtained for this study is done using findings from the primary data to design a green building using SketchUp. The sample frame for this study comprises the residents of Jakande Abesan (social housing) Estate, comprising of 1215 household units of two-and three-bedroom apartment. Thus, the total housing units of 1215 therefore serves as the sample frame for this study. Morris sample size formula is used to derive the sample size. Using Morris Sample Size, a total of 197 questionnaires were administered. Systematic random sampling is adopted in the administration of questionnaires to the residents of Jakande Abesan social housing estate. This method is most preferred for the study because it exempts bias from the choice of sample (building) been selected. An interval of Six (6) buildings per block is the administered questionnaire i.e., the $7^{\text {th }}, 13^{\text {th }}, 19^{\text {th }}, 25^{\text {th }}$, etc.

\subsection{Research Instruments}

Questionnaire and Computer applications (SketchUp) are used as the research 
instruments. The content of the questionnaire comprises of open and close ended questions for easy coding, tabulation, and subsequent analysis. The questionnaire comprises six sections, with details presented in Table 1.

\subsection{Data Analysis}

For data analysis, descriptive and inferential statistics is used in this study. The descriptive statistics include the use of frequency tables, cross-tabulations and charts. For accuracy, processing and analysing data is done using the Statistical Package for Social Sciences (SPSS) version 23. A summary of techniques and modes of measurement to attain the set objectives are summarized in Table 1.

It was observed that male respondents constituted more for the study (60.9\%) than female respondents (39.1\%). For this study, age bracket 40 - 49 (64\%), 30 $39(29.4 \%)$, and $20-29(11.7 \%)$, can be termed the active and most active working age bracket. Further details of the analysis can be found in Figure 1, and detailed discussion of this data has been given in Section 4 .

The data analysis and the subsequent discussion in Section 4 reveal that Jakande Abesan housing estate, is devoid of passive cooling, urban greenery, and adequate ventilation. In the sections that follow, a social housing design that integrates proper cross ventilation and cooling is proposed. The proposed design

Table 1. Method of Data Analysis. Source: Author's Field Survey, 2020

\begin{tabular}{|c|c|c|c|}
\hline Section & Objectives & Data Set & Method of Data Analysis \\
\hline 1 & $\begin{array}{l}\text { Socio-Economic } \\
\text { characteristics of } \\
\text { respondents }\end{array}$ & $\begin{array}{l}\text { gender, age, marital status, level of education, } \\
\text { employment status, occupation, average monthly } \\
\text { income, household size, and length of stay }\end{array}$ & $\begin{array}{l}\text { Descriptive statistics including; } \\
\text { frequency table, Pie and bar } \\
\text { charts, and Cross tabulations. }\end{array}$ \\
\hline 2 & Housing Characteristics & $\begin{array}{l}\text { Tenancy status, annual rent, age of building, number of } \\
\text { rooms, housing affordability, door type, window type }\end{array}$ & $-\ldots$ \\
\hline 3 & $\begin{array}{l}\text { State of Ventilation and the } \\
\text { Existing System Used for } \\
\text { Ventilation }\end{array}$ & $\begin{array}{l}\text { Number of windows in living and bedroom, condition of } \\
\text { windows, extent of ventilation, thermal condition, } \\
\text { passive cooling, availability of mechanical cooling } \\
\text { system, reason for purchasing mechanical cooling } \\
\text { system }\end{array}$ & - . - . - \\
\hline 4 & $\begin{array}{l}\text { The level of indoor comfort } \\
\text { derived from existing } \\
\text { ventilation available and the } \\
\text { system }\end{array}$ & $\begin{array}{l}\text { Number of fans, number of air conditioners, area with } \\
\text { most cooling systems, duration of operating cooling } \\
\text { system, time of day of operating cooling system, level of } \\
\text { comfort derived from using the natural ventilation } \\
\text { system, comfort derived from using mechanical cooling } \\
\text { system, availability of balcony, use of balcony. }\end{array}$ & $-\ldots$ \\
\hline 5 & $\begin{array}{l}\text { Impact of existing } \\
\text { ventilation systems on } \\
\text { residents }\end{array}$ & $\begin{array}{l}\text { Impact of ventilation system on residents, design and } \\
\text { social constraints of natural ventilation in the building. }\end{array}$ & $-\cdots-$ \\
\hline 6 & Housing Expectations & $\begin{array}{l}\text { Familiarity with the concept of green building, } \\
\text { willingness to pay for green building, building style, } \\
\text { preference for balcony, use of timber walls, landscaping. } \\
\text { Green building effects. }\end{array}$ & $\ldots \ldots$ \\
\hline
\end{tabular}




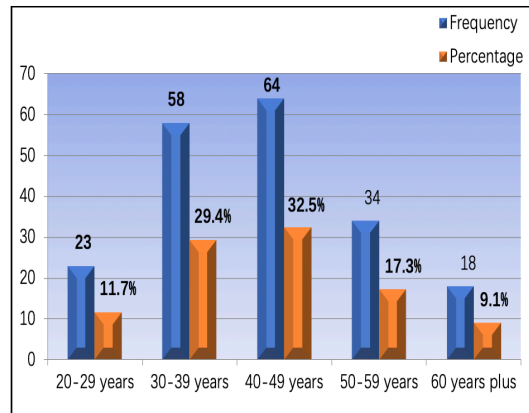

(a)

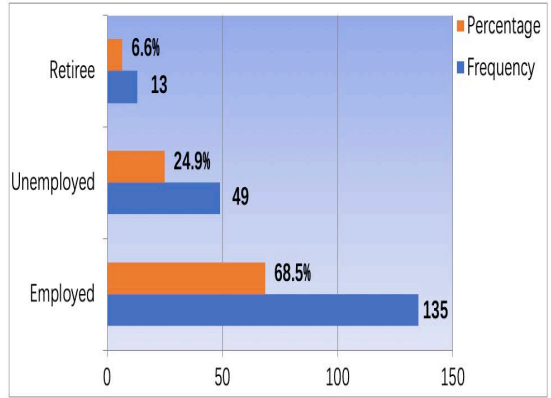

(c)

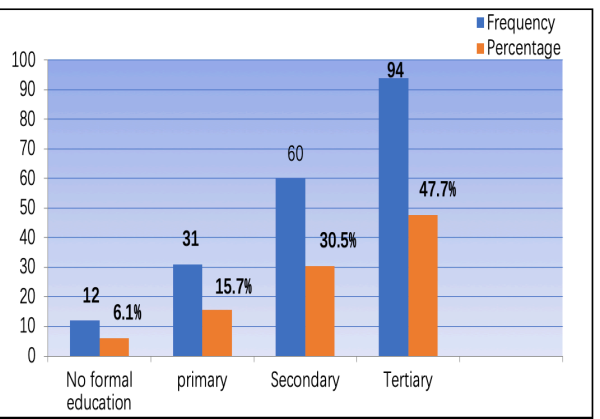

(b)

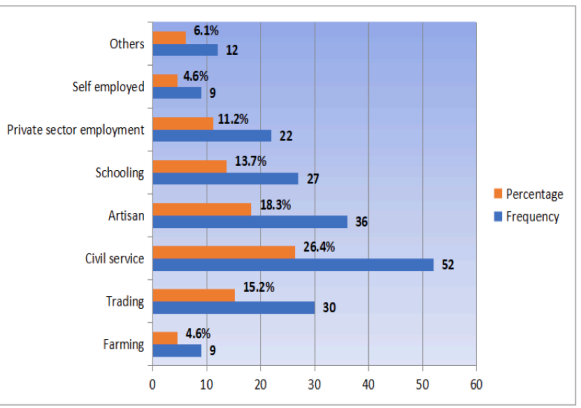

(d)

Figure 1. (a). Age Distribution of Respondents. (b). Educational Level of Respondents (c). Employment Status of Respondents. (d). Occupation Type of Respondents. Source: Author's Fieldwork, 2020.

methodology aids continuous cooling within the housing unit and enhances aesthetics and landscaping within the building environment.

\section{Design and Simulation}

\subsection{Floor Plan Designs (2-Bedroom and 3-Bedroom Apartments)}

This is a proposed prototype for the Jakande Abessan Estate. An addition of two floors was added to the initial design of the buildings in the estate. This is in line with meeting social housing requirements such as more housing for the low-income earners, reduce any form of overcrowding that may persist, and going higher for a cooler atmosphere. This design was done to fit into the surrounding neighborhood and to work with natural features to provide shade for the building, improve natural ventilation and cooling, through proper orientation of windows and building. Figure 2 shows the proposed designs.

Vegetation and trees in particular, very effectively shade and reduce heat gain. This proposed greenery can be used with advantage to shade roof, walls and windows. Shading and evapotranspiration from trees can reduce surrounding air temperatures as much as $5^{\circ} \mathrm{C}$. In essence, this greenery in the layout of the buildings will enhance ventilation, provide a means to capture thermal mass. Also, to improve air quality, internal windows are installed on the walls of each room, except for the one bedroom self-contain of the $4^{\text {th }}$ and $5^{\text {th }}$ floor. This concept was adapted after series of simulations to enhance indoor natural circula- 
tion, and to complete a full cross ventilation cycle. This concept is shown in

Figure 3.

GROUND FLOOR ( 2 BEDROOM APARTMENTS)

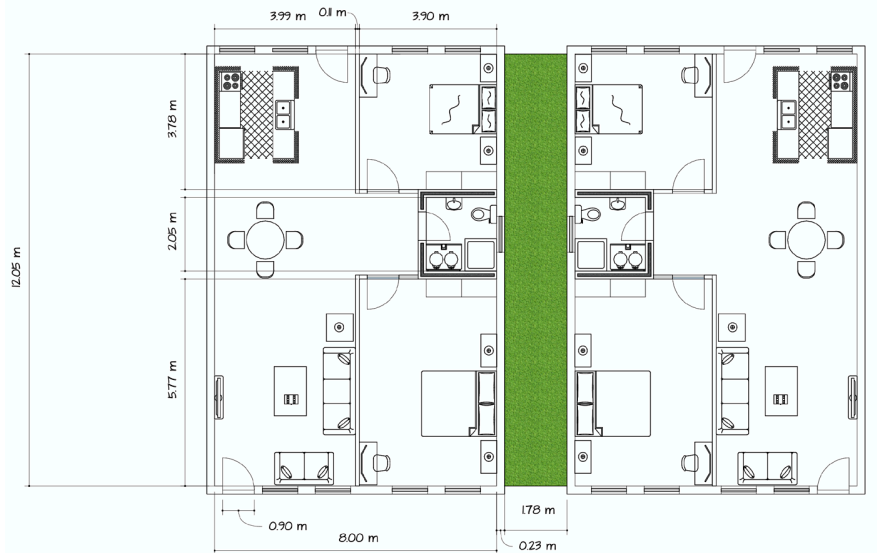

(a)
1,2,3RD FLOOR ( 3 BEDROOM APARTMENTS)

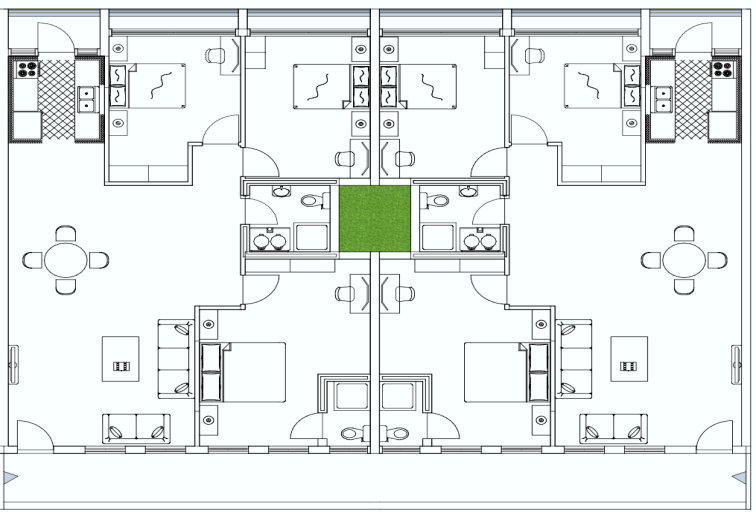

(b)

4, 5TH FLOOR ( 2 BEDROOM APARTMENTS + 1 BED SELFCON)

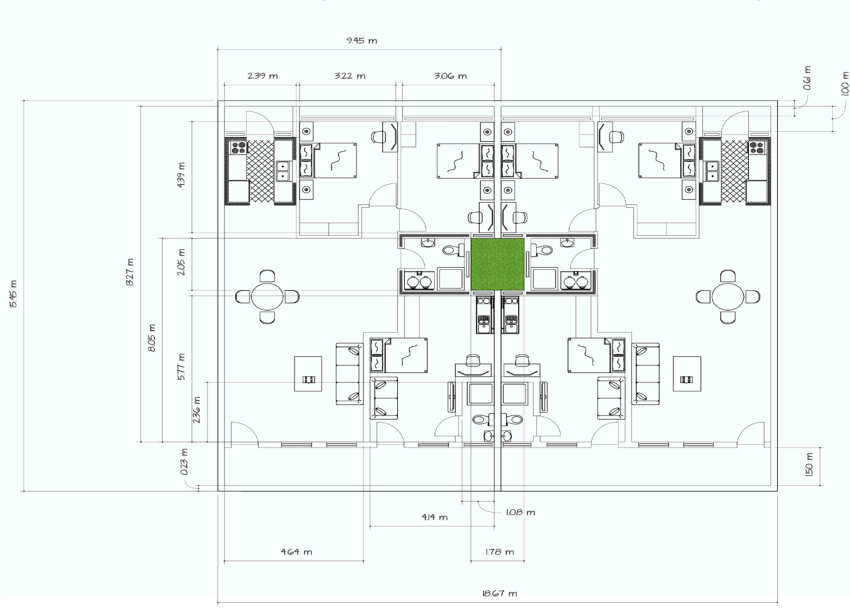

(c)

Figure 2. (a). Proposed ground floor plan (2-bedroom apartments). (b). Proposed first, second and third floors (3-bedroom apartments). (c). Proposed fourth and fifth floor plan (2-bedroom apartments and self-contain). Source: Author's Fieldwork, 2020.

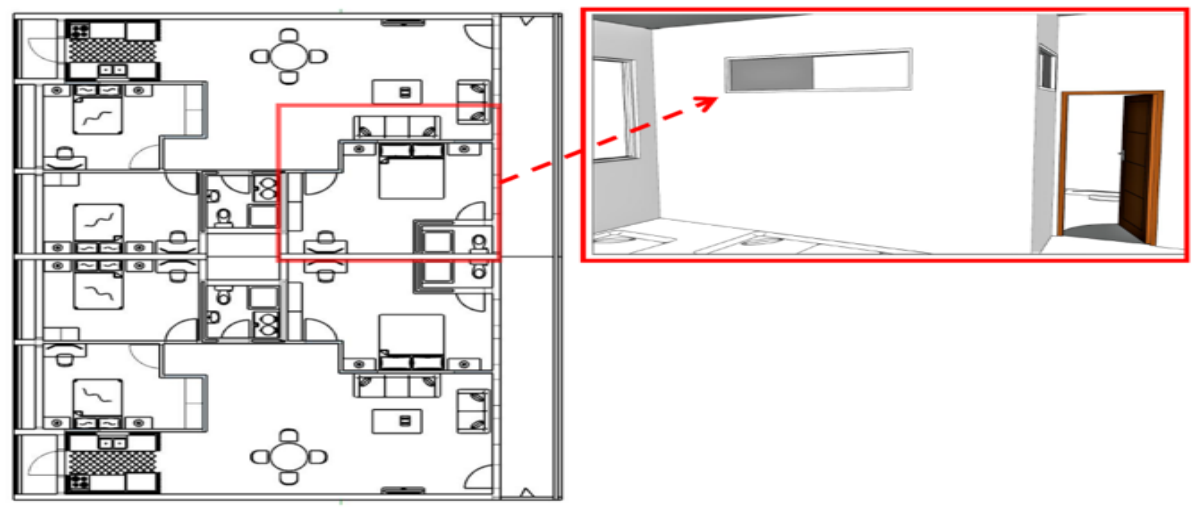

Figure 3. Proposed internal windows. Source: Researchers' design. 


\subsection{Proposed Elevations to Improve Ventilation}

The design proposes the use of sliding windows for ventilation as compared to the existing windows which consisted of woods, and had no consideration for air filtering. Figures 4-6 reveal the proposed front and rear elevations, which were designed, with the aim of giving access for cross-ventilation, and orientating the windows to natural lighting. Figure 7 is a proposed elevator and stairs which was carefully orientated to ensure passive cooling and lighting even when electric power is unavailable. These proposed elevator and stairs are improvement on the existing pathway or corridor, which the initial design failed to incorporate cooling consideration, likewise lighting. The proposed elevator and stairs have

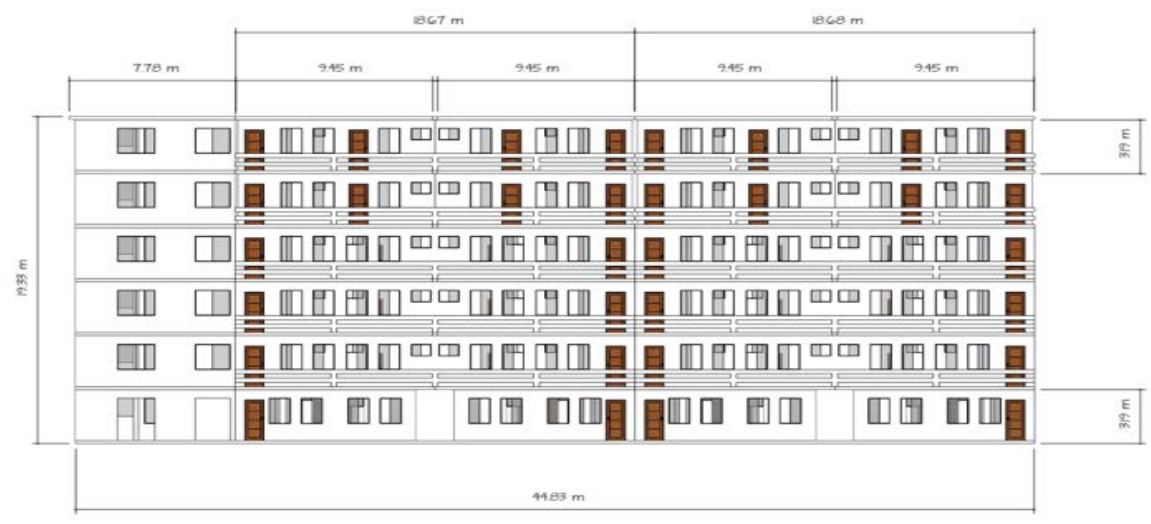

Figure 4. Proposed front elevation. Source: Researchers' design.

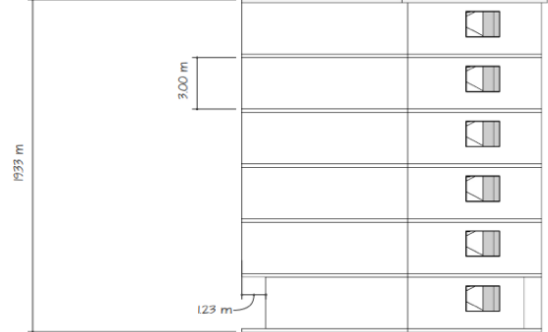

(a)

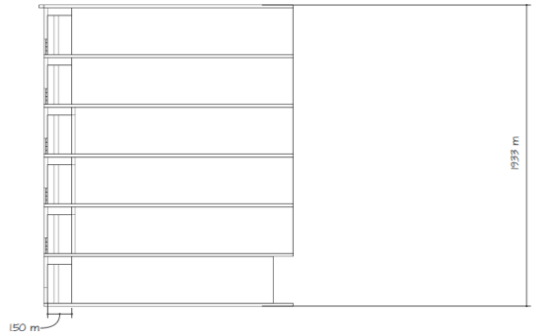

(b)

Figure 5. (a) Proposed right elevation. (b) Proposed left elevation.

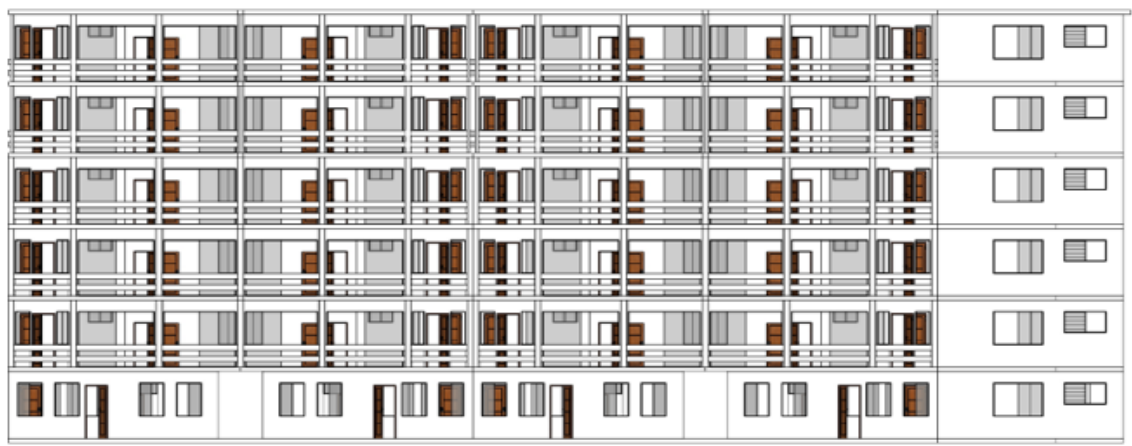

Figure 6. Proposed Rear elevation. Source: Researchers' design. 
more opening and transparency giving room for ventilation.

\subsection{Cross Ventilation and Room Comfort Simulations}

This section gives a simulation report on the room comfort and cross ventilation through well-annotated architectural massing designs and layouts. A summarized report on the room ventilation and velocity analysis is given below. In the simulation, all internal windows were shut and Wind speeds were set to $4.7 \mathrm{mph}$ $(2.107 \mathrm{~m} / \mathrm{s})$. Result shows a peak wind speed of $4.7 \mathrm{~m} / \mathrm{s}$, while for the condition where all windows were opened with equivalent parameters, a peak wind speed of about $5-4 \mathrm{~m} / \mathrm{s}$ at a stabilized flow was seen. The application of wind speed of $4.7 \mathrm{mph}$ was informed by the fact that we are operating at standard atmospheric temperature and pressure. Figure 8 depicts the vertical cross section of the building, showing areas where air circulation impacts the design. Finally, Figures 9-14 show the glyphs for cross ventilation of various floors.

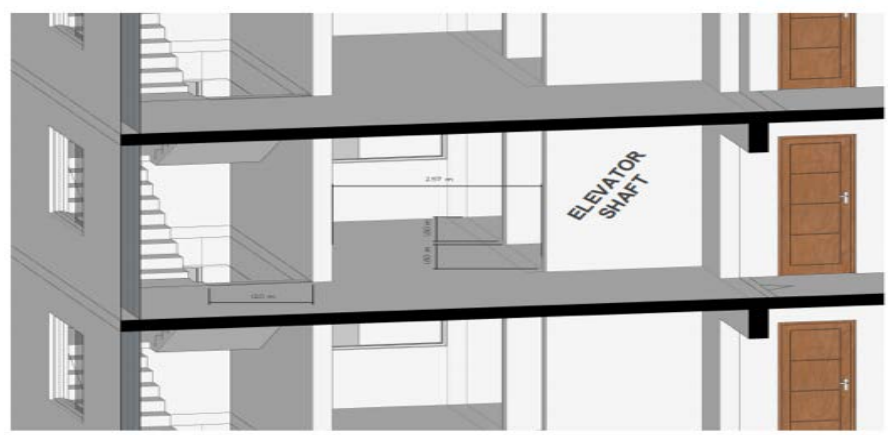

Figure 7. Proposed Elevator and stairs. Source: Researchers' design.

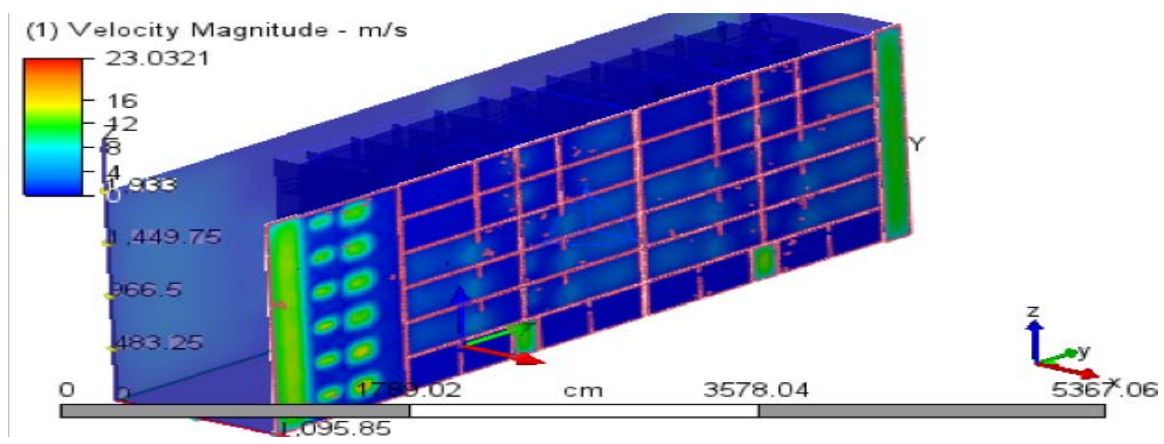

Figure 8. Vertical cross section of the building showing areas where air circulation impacts the design. Source: Researchers' design.
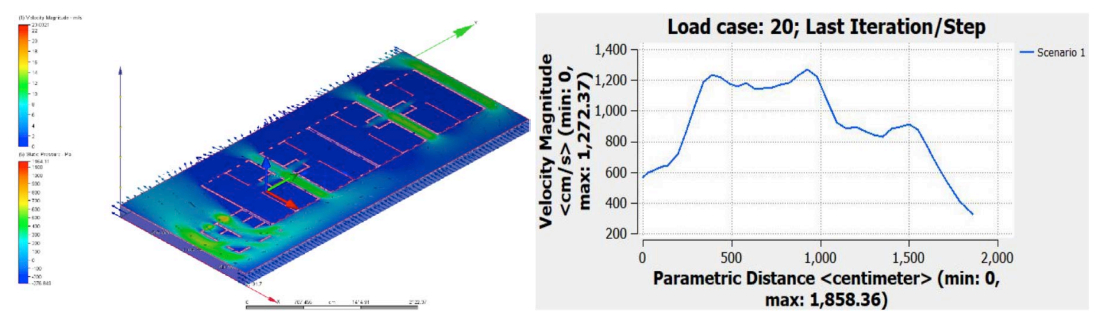

Figure 9. Ground floor cross ventilation glyph. 

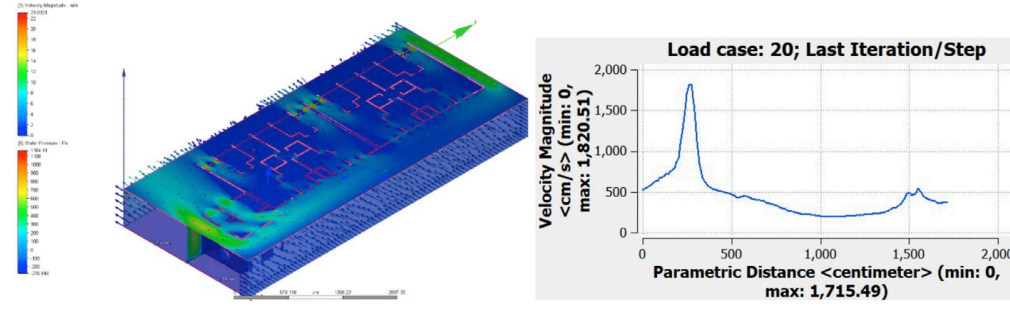

Figure 10. First floor cross ventilation glyph.
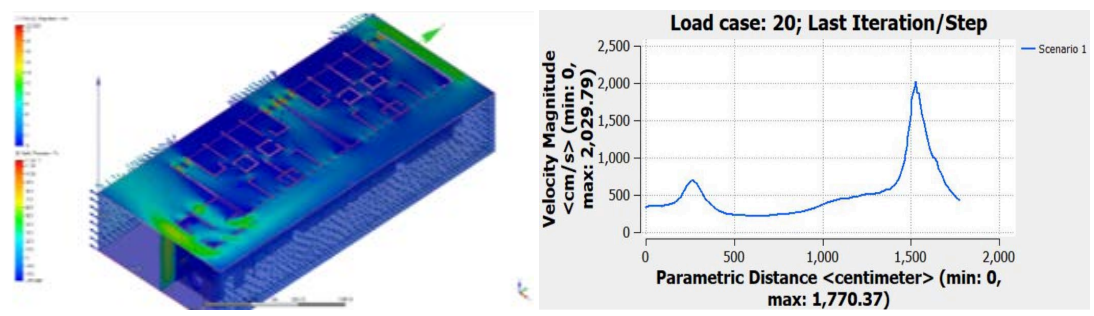

Figure 11. Second floor cross ventilation glyph.
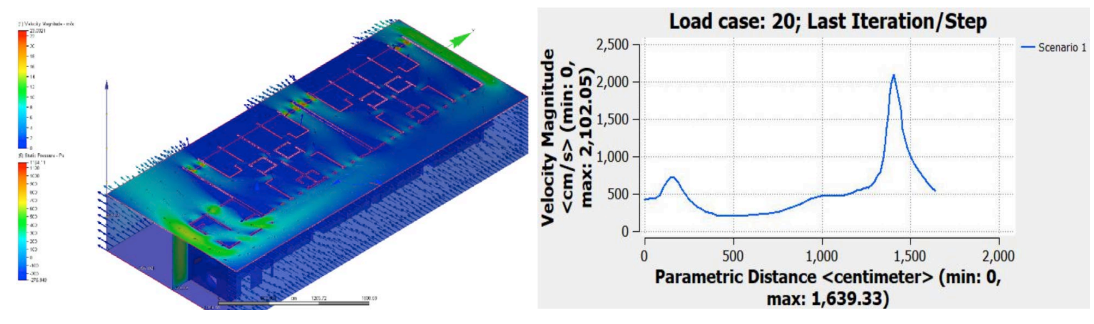

Figure 12. Third floor cross ventilation glyph.
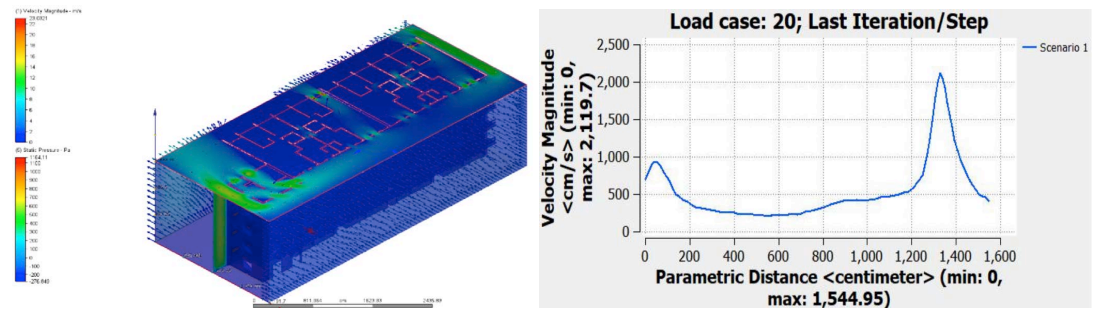

Figure 13. Fourth floor cross ventilation glyph.
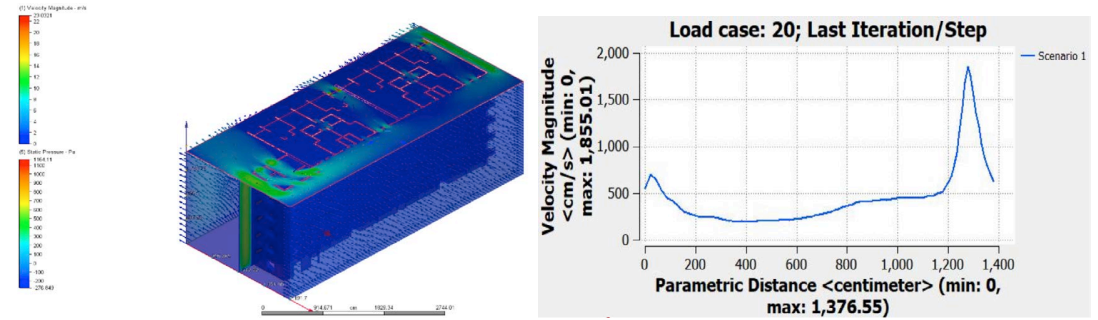

Figure 14. Fifth floor cross ventilation glyph.

\section{Discussion}

The attempt in this section is to draw inferences from the data analysis and elucidate the findings using a format that is constructive and beneficial for policy implementations. It is followed by recommendations, to solving issues associated 
with ventilation. A number of deductions were made from the data analysis in Section 2. These are highlighted as follows. Analysis of gender reveals that male respondents constituted more for the study (60.9\%) than their female counterparts $(39.1 \%)$. This large variation streamed from the readiness and availability of both sexes during the period of questionnaire administration. Age analysis showed that age bracket $40-49(64.0 \%)$ and $30-39$ (29.4\%) constituted the most significant active age bracket for the study. The marital status analysis disclosed that married (64.5\%) and single (23.9\%) respondents are most significant for the study. It was observed that $(47.7 \%)$ of the respondents are tertiary certificate holders, comprising the most significant on education analysis. This analysis is true as (68.5\%) of the respondents are gainfully employed in either formal or skilled labour employment. A breakdown on occupation type revealed that (26.4\%) of the respondents are civil servants (been the most significant), artisans (18.3\%), traders (15.2\%), schooling (13.7\%), private sector (11.2\%) among others. As presented, it can be inferred that level of education influences employment status and thus occupation type. Household size analysis revealed that household capacity comprising of $6-8$ persons (37.6\%) and $3-5$ persons (31.5\%) are most significant as compared with household 9 - $11(18.8 \%)$, less than $2(8.6 \%)$ and above 12 persons (3.6\%). The household size of $6-8$ persons is the most significant for the study and therefore termed overpopulated concerning housing unit capacity. Further analysis indicated that respondents who have been residing in Jakande Abesan for $11-16$ years (35.5\%) and $16-20$ (25.4\%) are the most significant as compared to respondents who have only lived for 6 - 10 years (20.8\%), less than 5 years (13.2\%) and 20 years above (5.6\%). Further analysis showed that buildings within the age group 10 - 20 years $(82.2 \%)$ are most significant for the study as compared with buildings less than 10 years $(15.2 \%)$ and 20 - 30 years $(2.5 \%)$. This does not only show that the buildings within Jakande Social housing are not structurally fit, but are defaced and unaesthetic lacking adequate maintenance culture and proper monitoring. From the analysis, 2-floor buildings (95.4\%) are most significant for the study as compared with the 3 -floor buildings (4.6\%). This infers that the existing layout plan of Jakande Abesan social housing comprises more 2-floor residential buildings than 3-floor buildings. Furthermore, the analysis disclosed that 2-bedroom apartment is the most significant for the study (95.4\%) and tend to pay a cheaper rent as compared with 3-bedroom apartment (4.6\%) which is least significant and tend to pay a higher rent. On housing affordability $65.4 \%$ of the respondents find their housing units unaffordable and too costly to meet up with while $15.3 \%$ finds their housing unit quite affordable. This corroborates the findings on the annual rent. Furthermore, analysis on door and window condition revealed fair (59.9\%) as the most significant as compared with poor (32.0\%) and good condition $(8.1 \%)$. As discovered in the survey, $84.2 \%$ of the respondents stated that their rooms, kitchen, Toilet/bath are not well ventilated. This analysis is true as study revealed that $95.9 \%$ of the respondents attested to the fact that they experience long-duration heat in their building/apartment. All respondents (100.0\%) 
affirmed the availability of a mechanical cooling system within their building envelope. (76.1\%) of the respondents own more fans (a mechanical ventilation system) as compared to air conditioners (23.9\%). Also, (45.7\%) believes mechanical ventilation is necessary, while (13.2\%) believes there is a need for an extra cooling system aside from natural ventilation. Disclosed from the survey, $87.3 \%$ of the respondents owned 3 to 5 fans while $12.7 \%$ owned less than two fans. Furthermore, it was discovered that $(82.2 \%)$ of the respondents do not own air conditioners while (17.8\%) have possession of air conditioners. It can thus be inferred that possession of fans is most significant for the study because fans are cheaper and easier to maintain while air conditioners are expensive both in cost and maintenance. Furthermore, (93.4\%) of the respondents prefer locating their cooling system in the living room while (6.6\%) prefer locating their cooling system in the bedroom. As analyzed from the survey, $24.4 \%$ of the respondents has a preference for night operation while (75.5\%) prefer running cooling systems all day in as much electric power is constant. (66.5\%) of the respondents run their cooling system for 8 - 12 hours, (23.4\%) run their cooling system for 4 - 8 hours, and $(10.2 \%)$ run for $1-4$ hours per day. $66.5 \%$ prefer a daily window opening and $(33.5 \%)$ prefer night window opening. Choice of the window opening is dependent on the period/duration spent at home or outside. Furthermore, analysis showed that (91.9\%) of the respondents are not satisfied with the level of comfort derived from natural ventilation. This relates to the analysis that a moderate comfort level (57.4\%) is derived from cooling systems. From the analysis (27.4\%) of the respondents stated increased cost of running air conditioning system as a major impact, (31.4\%) stated increased energy consumption, (17.8\%) stated problem of sick building syndrome (SBS). SBS occurs as a result of spending long hours in a damp or moist environment. The SBS includes symptoms such as eye, nose, throat, and skin irritation; nasal congestion (stuffy, blocked nose); nasal excretions (runny nose); cough; wheeze; tight chest; mental fatigue; headache; nausea and dizziness. According to the findings, the occurrence of SBS is influenced by the characteristics of buildings and ventilation systems. From the analysis (37.1\%) stated old building design as a major constraint, $(21.3 \%)$ stated poor positioning of lightning and ventilation, (19.3\%) stated poor land-use planning and management, and (15.2\%) stated rigid design. Analysis showed that (97.5\%) of the respondents are not familiar with the green building design concept. From the analysis (40.6\%) prefer wetted plants within their building to improve comfort, (55.3\%) prefer timber for internal walls, and (35.5\%) prefer landscaping of building with greenery.

From the above discussion, it is obvious that the buildings within Jakande Estate need both renovation and reconstruction. In Section 3, a passive cooling design approach has been presented.

\section{Conclusions}

On the basis of a survey conducted on 1215 housing units in the Jakande housing estate, this paper proposed an analytical housing design equipped with urban 
greenery that allows for free air movement with minimal thermal discomfort. The concluding remarks have been summarized below:

1) From the survey, it was revealed that the majority of facilities (96.4\%) consisted of 3 floors. A redesign of the estate housing has been presented in Section 3. An addition of two floors was added to the initial design of the buildings in the estate. This is in line with meeting social housing requirements.

2) In the survey, all sampled residents had electric fans as a cooling system, with the majority (45.7\%) considering it as indispensable. $75.6 \%$ used their existing cooling system for as long as 8 to 12 hours in a day provided there was power, which increased the cost of energy consumption. The survey showed that $91.9 \%$ of the respondents were not satisfied with the comfort level derived from natural ventilation. The proposed design in Section 3 resolve this problem by providing a proper landscaping for energy conservation in the buildings.

3) As revealed in the survey, $84.2 \%$ of the respondents stated that their rooms, kitchen, Toilet/bath are not well ventilated. In the proposed housing design of Section 3, this issue is resolved by providing ventilation within the building envelope. To improve air quality, internal windows are included on the walls of each room. This concept is shown in Figure 3. The design in Section 3 also proposes the use of sliding windows for ventilation as compared to the existing wooding ones, which had no consideration for air filtering.

4) The unique value of this research is immense as the proposed design provides solutions to some of the prominent problems within the Jakande Estate which include; absence of urban greenery, blighted landscape cover and vegetation, defaced buildings, and lack of ventilation, high cost of energy consumption and so forth. The study also serves as a roadmap for the construction of affordable green social housing facilities in most developing countries in Africa.

\section{Conflicts of Interest}

The authors declare no conflicts of interest regarding the publication of this paper.

\section{References}

[1] Im, E.S., Pal, J.S. and Eltahir, E.A. (2017) Deadly Heat Waves Projected in the Densely Populated Agricultural Regions of South Asia. Science Advances, 3, No. 8.

[2] Hwang, B.G., Zhu, L. and Ming, J.T.T. (2017) Factors Affecting Productivity in Green Building Construction Projects: The Case of Singapore. Journal of Management in Engineering, 33, 04016052. https://doi.org/10.1061/(ASCE)ME.1943-5479.0000499

[3] World GBC (2021) What Is Green Building? https://www.worldgbc.org/what-green-building

[4] Darko, A. and Chan, A.P.C. (2016) Critical Analysis of Green Building Research Trend in Construction Journals. Habitat International, 57, 53-63. https://doi.org/10.1016/j.habitatint.2016.07.001

[5] Golubchikov, O. and Badyina, A. (2012) Sustainable Housing for Sustainable Cities: A Policy Framework for Developing Countries. UN-HABITAT, Nairobi, Kenya Availa- 
ble at SSRN. https://ssrn.com/abstract $=2194204$

[6] Ojoko, E.A., Halimat, O.A. and Oga, O. (2016) Sustainable Housing Development in Nigeria: Prospects and Challenges. JMEST, 5, 2458-9403.

[7] Oucho, J. (1998) Recent Internal Migration Processes in Sub-Saharan Africa: Determinants, Consequences and Data Adequacy Issues. In: Bilsborrow, R.E., Ed., Migration, Urbanization, and Development: New Directions and Issues, United Nations Population Fund (UNFPA) and Kluwer Academic Publishers, New York, 89-120.

[8] Daramola, A. and Ibem, E.O. (2010) Urban Environmental Problems in Nigeria: Implications for Sustainable Development. Jrl. of Envron. Sciences, 12, 1520-5509.

[9] Fadare, S. and Oduwaye, A. (2009) Rebranding Lagos through Regeneration. Real Corp Book of Proceedings on Cities, 3, Lagos, Nigeria.

[10] Electricity: Over 50\% Customers Unmetered 4yrs after Privatization. https://www.dailytrust.com.ng/electricity-over-50-customers-unmetered-4yrs-afterprivatisation.html

[11] Ejigbo Community Insists on Pre-Paid Meters. https://www.vanguardngr.com/2017/03/ejigbo-community-insists-pre-paid-meters/

[12] Wang, W., Zhang, S., Su, Y. and Deng, X. (2018) Key Factors to Green Building Technologies Adoption in Developing Countries: The Perspective of Chinese Designers. Sustainability, 10, 4135. https://doi.org/10.3390/su10114135.

[13] Jani, D.B. (2019) An Overview on Passive Cooling Systems in Green Building Architectures. Open J Archit Eng., 1, 1-15.

[14] Gioregetti, L. (2010) Sustainable Building Practices for Low Cost Housing. Implication for Climate Change Mitigation and Adaptation in Developing Countries, Draft, 4, 3043-3048. 